\section{The Impact of Mindfulness-Based Yoga Interventions on Fifth-Grade Students' Perceived Anxiety and Stress}

\author{
Alicia Cooper Stapp ${ }^{\mathrm{a},{ }^{*}}$, Ashley Berry Lambert ${ }^{\mathrm{b}}$
}

\author{
Received: 18 March 2020 \\ Revised: 23 May 2020 \\ Accepted: 13 June 2020 \\ ISSN: 1307-9298 \\ Copyright (C) IEJEE \\ www.iejee.com
}

DOI: 10.26822/iejee.2020562137

\begin{abstract}
With rising pressure and an increase in expected academic performance in schools across the United States, students are experiencing higher levels of stress than ever before. To address this issue, the present study examined the impact of mindfulness-based yoga interventions on fifth-grade students' perceived anxiety and stress levels through a mixed methods research approach. Quantitative data were collected from students through a pre- and post-questionnaire while qualitative data were garnered through an interview with the classroom teacher. Findings revealed that following the intervention period, students reported a slight increase in anxiety levels (1.9\%) and a decrease in stress levels (9.29\%). Particulrly, males in the remedial class displayed changes in both a decrease in anxiety (31.58\%) and stress (16.68\%) levels. Additionally, the following themes emerged from the qualitative data: (a) teacher perceptions of students' anxiety and stress in the classroom; (b) transfer of mindfulness-based yoga skills; and (c) creating a positive transition. These results suggest that mindfulness-based yoga can be a positive tool for the classroom to reduce students' anxiety and stress.
\end{abstract}

Keywords: Mindfulness-Based Yoga, Anxiety, Stress, Elementary Classroom

\section{Introduction}

The No Child Left Behind Act was signed into law in the United States in 2002 with the goal of holding schools accountable for the academic progress of all students (No Child Left Behind [NCLB], 2002). Part of the accountability plan was the inclusion of yearly mandated assessments on reading and mathematics beginning in the third grade. To increase the stakes and propel schools toward even higher academic achievement, the Race to the Top initiative was introduced in 2009. This initiative placed states against each other to compete for federal education grants, as funding was based on states' test scores. Replacing the No Child Left Behind Act, the Every Students Succeeds Act was passed in 2015 and supported the mandatory testing set forth in the No Child Left Behind Act (Every Student Succeeds Act [ESSA], 2015). These yearly assessments compelled teachers and administrators to place more emphasis on tested subjects. Subsequently, sedentary instructional time increased, while time allotted for students to participate in non-tested subjects and activities that provide more active outlets decreased (Dee \& Jacob, 2010; Kohl \& Cook, 2013). Due to both federal instructional mandates and increased sedentary behaviors during the school day over the past couple of decades, students have exhibited difficulties focusing on instructional tasks in the classroom, which has hindered their abilities to perform academically (Reilly et al., 2012). A lack of effective intervention strategies to assist students with attentiveness during instruction is compounded by the extensive amount of stress and pressure students experience to perform well (Hagen \& Nayar, 2014). Although academic expectations have risen considerably, very few adopted and consistent interventions or programs are available for students to reset their brains and bodies during classroom instruction in order to manage rising pressures.

One approach to increasing attention in the classroom that has steadily gained momentum over the past decade is the practice of mindfulness. While mindfulness is an emerging trend for classroom teachers, a deficiency still remains in the literature regarding effective mindfulness practices in the elementary classroom. Moreover, even less research exists on effective mindfulness-based yoga interventions for the classroom.

\section{Mindfulness}

Definitions of mindfulness vary by practice or researcher, but a consistent theme in all definitions is the intentional focus and awareness on one's present environment. Researchers at The University of California Berkeley noted that it includes a non-judgmental thought process with the knowledge that there is no correct way to think or feel in any given moment ("What is Mindfulness," n.d., para. 2). The word "mindfulness" is a translation of the Sanskrit word "smrti," meaning remembering and recollecting, particularly remembering the teachings of Dhamma (Sharf, 2015, p. 473). It is an internal practice rooted in Buddhist meditation and is often seen in yoga and tai chi. Sharf (2015) stated that early Buddhist beliefs expressed a need for suffering in life; in order to relieve this suffering, one must escape this world. Mindfulness was practiced to abandon the good and happiness of the world in order to cultivate that suffering. However, the evolution of these beliefs has progressed towards a stronger focus on happiness. Mindfulness practices are now considered a therapeutic release in search of peace and fulfillment (Sharf, 2015). Furthermore, the practice of mindfulness has become more common in Western culture and recent studies reveal the emotional, social, and physical benefits that arise when students practice mindfulness (Ager et al., 2015).

\section{Mindfulness in the Classroom and School Setting}

As studies centered on exploring the benefits of mindfulness in adults become more prevalent, researchers have turned their attention to students in the school setting. Similar to adults, mindfulness can benefit all aspects of students' lives. Even though many believe that the classroom is only meant 
for academia, students' developmental domains must be met before they can focus on learning (Lund, 2010). Implementing mindfulness-based interventions into the classroom and school setting has the potential to address all of these domains. Examples of mindfulness school-based programs that have emerged over the past decade to address students' needs are the Master Mind Program (Parker et al., 2014) Mindful Schools (Mindful Schools, 2007), and Open Circle Program (Open Circle, n.d.b.). Additionally, applications such as Calm (Calm.com Inc, 2020) and Headspace (Headspace Inc. 2020) are available for parents or teachers to download directly onto their phone.

\section{Effects of Mindfulness on Self-Regulation}

The practice of mindfulness fosters thoughtful responses rather than immediate actions, which can improve reactions to the daily obstacles and stressors students encounter at school (Parker et al., 2014; Pepping et al., 2013). Moreover, when students utilize mindfulness strategies, they can improve their self-control and self-regulation, directing them away from poor decisions (Parker et al., 2014). Mindfulness can also be cultivated through the practice of yoga, which adds a physical element to mindfulness practices. Students often struggle with monitoring their reactions and decisions, but practicing yoga can foster students' ability to self-regulate their emotions and stressors by enabling them to take a step back to focus and understand what is going on around them prior to reacting (Razza et al., 2013). Ultimately, students become more aware of their thoughts and emotions, and utilize that awareness to respond positively to various situations (Parker et al., 2014).

One study analyzed mindfulness-based interventions on self-regulation in an urban classroom of 29 preschool students - 16 students were in the intervention group and 13 students were in the control group (Razza et al., 2013). A pre- and post-test measured students' self-regulation and was completed by both parents and students. Following the pre-test, the intervention group received yoga instruction in their classroom, while the control group did not receive yoga instruction. Post hoc, both groups were given a series of tests that observed their attention, delay of gratification, and inhibitory control. Results indicated that the students who received yoga instruction exhibited increased attention and inhibitory control (Razza et al., 2013). These findings reveal the vital impact mindfulness-based yoga can have on self-regulation, as it helps students remain calm, alert, and focused on the task at hand (Blair \& Razza, 2007).

\section{Effects of Mindfulness on Anxiety}

Stress also can negatively affect students at school. Particularly, students experience increased stress during test-taking situations (Jones et al., 1999; Jones \& Egley, 2004). Carsley et al. (2015) examined students' anxiety prior to a spelling test. Participants were 152 fourth, fifth, and sixth-grade students. Half of the students completed a mindful activity before their spelling test, while the remaining half participated in a free draw activity before their spelling test. Findings revealed that both the mindful coloring activity $(p=.006)$ and the free draw group ( $p=.007)$ experienced a significant decrease in anxiety.

In another study, 25 students utilized mindfulness-based cognitive therapy (Semple, 2010). Participants were between nine and thirteen years of age and were enrolled in a reading program for remedial students. Throughout the study, the students practiced seated breathing techniques and body meditations. They also practiced bringing mindful attention to their thoughts and emotions. Students who initially showed high levels of anxiety at the beginning of the study showed a significant reduction in anxiety levels and negative behaviors at the end of the study $(p=.02 ; d=.38)$.
Another study examined how students felt about the implementation of Meditation Capsules: A Mindfulness Program for Children (Ager et al., 2015). The students kept reflective journals throughout the duration of the study where they were asked to describe their thoughts and feelings about the mindfulness sessions, draw pictures that represented their feelings, illustrate their favorite parts of the mindfulness program, or describe when the use of mindfulness could be helpful. Findings revealed that mindfulness improved the overall well-being of students because they were more aware of their feelings. It was also noted that students were able to self-assess when they needed to utilize guided breathing and mindfulness which helped them manage their anxiety and stress (Ager et al., 2015).

\section{Effects of Mindfulness on Stress}

As expectations for academic achievement and standardized testing performance rise, many students also experience an increased amount of stress (Hagen \& Nayar, 2014). Stueck and Gloeckner (2007) addressed this issue by conducting a study that examined the emotional well-being of 48 fifth-grade students who participated in yoga classes. Students began each class with a period of relaxation where they focused on being mindful of their body, followed by a session of yoga. Throughout the study, students learned 23 different yoga exercises. The end of class focused on the students' social well-being as students were partnered together to complete trust exercises and sensory games. Results indicated that students reported a decrease in feelings of helplessness, stress, and aggression. The students also showed more positive behaviors in the classroom and an increased control over emotions after the implementation of yoga (Stueck \& Gloeckner, 2007). Similarly, Mendelson et al. (2010) examined the stress and mental health of fourth and fifth-grade students. Students were introduced to yoga-based physical activity, breathing techniques, and guided mindfulness practices over a 12-week period. Findings from the study's questionnaire indicated a positive impact on stress levels. One participant claimed that the program helped her learn different strategies to use at home to help lower stress levels, while another participant noted that the program helped him learn to cope with stress in a healthier way (Mendelson et al., 2010).

\section{Physical Benefits of Mindfulness-Based Yoga}

The physical benefits of yoga in the literature is predominantly focused on adults; however, the practice of yoga may also be helpful for students' body awareness and brain development. Broderick and Metz (2009) conducted a study in a Catholic, allgirls school which revealed the benefits of mindfulness in the classroom through a series of interviews and pre- and posttests. The central foci of the study was on body awareness, understanding one's feelings, thoughts, and bodily sensations. Participants reported considerable reductions in tiredness and stated that they felt a decrease of general aches throughout their body (Broderick \& Metz, 2009).

Studies have also shown significant gains in motor development for students through yoga programs (Donahoe-Filmore \& Grant, 2019; Folleto at al., 2016). Folleto et al. (2016) conducted a study that examined 16 first-graders' balance, strength, and flexibility. Student participants completed a 12week intervention that consisted of two 45-minute yoga sessions a week. A motor proficiency test was administered to determine any changes in students' motor abilities. Following the interventions, students showed positive changes in balance, strength, and flexibility. A similar study conducted by Donahoe-Fillmore and Grant (2019) examined the balance, strength, coordination, and flexibility of 26 students, ages 10 12. Students participated in 40-minute yoga classes one to three times a week for eight weeks. A motor proficiency test was employed to measure any changes. Findings showed sta- 
tistically significant changes in balance $(p=.06)$ and flexibility (popliteal angle right, $p=.005$; popliteal angle left, $p=.01$ ); however, there was no significant change in strength.

\section{Cognitive Benefits of Mindfulness}

It has been noted that those who practice mindfulness have "measurably thicker brains" (Hanson, 2011, para. 15) in the insula region, the frontal region of the prefrontal cortex, and the somatosensory cortex. Providing evidence to these claims, Hanson (2011) conducted a cohort study to compare the brain thickness of those who practiced mindfulness meditation and those who did not. Participants who did not practice mindfulness experienced thinning of the brain, or cortical thinning, which is typical with aging. Results also indicated that participants who did practice mindfulness did not experience cortical thinning. Conversely, their brain remained the same thickness even as they aged (Hanson, 2011).

A systematic review of nineteen studies on the cognitive benefits of mindfulness evaluated 1,348 students in first through twelfth grade. Results indicated the cognitive performance between groups was statistically significant ( $p<$ .05) (Zenner et al., 2014). Another study focused on the relationship between mindfulness and assessment scores (Bellinger et al., 2015). Participants were undergraduate students who were asked to listen to recordings of mindful breathing exercises and complete a questionnaire which examined their anxiety and mindfulness. At the conclusion of the recordings and questionnaires, participants completed a set of math problems. Findings revealed that participants completed the problems with more accuracy following the intervention because of a decrease in test anxiety. Another study analyzed selective attention and test anxiety. First, second, and third-grade students participated in a 24-week Attentive Academy Program which was designed to improve their life through the practice of mindfulness (Napoli et al., 2005). Students completed pre- and post-measures including a Test Anxiety Scale and Test of Everyday Attention for Children subtests. At the conclusion of the program, a statistically significant change in both selective attention $(p=.001)$ and test anxiety ( $p=.007$ ) was revealed, thus showing the possible benefits of mindfulness within schools (Napoli et al., 2005).

\section{Benefits for Classroom Teachers}

Teachers also face high levels of anxiety and stress in their daily lives, which can affect the classroom environment (Herman et al., 2017). One study revealed that some teachers struggle managing stress related to students who lack motivation, student discipline, workload, constant changes, evaluations, administration, self-esteem, and poor work conditions (Kyriacou, 2001). A teacher's attitude and behavior can even affect students' learning and the quality of the overall classroom. Studies have revealed that students in classrooms with positive teacher-student relationships are more engaged and perform better in school (Eccles \& Roeser, 2004; Holas \& Huston, 2012). Therefore, interventions that address the anxiety and stress of both students and teachers could be deemed highly instrumental in classroom success. For example, a special education supervisor in Pennsylvania stated that before her middle school implemented yoga there was a much higher teacher turnover rate. Since the implementation of yoga, the turnover rate has decreased dramatically (Garey, n.d.). With hyperactive and restless students, teacher attrition was an issue, until mindfulness was introduced into the school's classrooms. The students began practicing awareness of the "attention to breath, how different parts of their bodies feel, how their feet connect to the floor, their seats to their chairs, and... the present moment" (Garey, n.d., para. 4). Through these practices, students became calmer and more capable of self-regulating, making their education and their teachers' work more enjoyable and effective.

\section{Current Mindfulness-Based Programs}

Considering the well-established benefits of practicing mindfulness, schools have begun to adapt mindfulness-based programs. Several programs have been developed in an effort to implement mindfulness practices into classrooms across the United States. One program, Open Circle, was created for kindergarten through fifth-grade. The curriculum encompasses five topics - beginning together, managing ourselves, strengthening relationships, how to sort problems, and problem solving (Open Circle, n.d.a). Mindfulness is found throughout the curriculum within activities such as "calm breathing techniques, pause button, partner reflections, chair yoga, 3-minute breathing space, walking meditation, and what color are your feelings?" (Open Circle, n.d.c). Open Circle believes that "mindfulness is a key support for optimal learning" (Open Circle, n.d.c, para 1). Hennessey (2006) examined the benefits of the Open Circle Program on eight fourth-grade classrooms across four different schools. After utilizing Open Circle for an academic year, teachers reported significant changes in social skills $(p=.001)$ and problem behaviors $(p=.001)$, particularly for students in urban schools.

Another program, Mindful Schools, focuses on "under-resourced public schools facing high turnover rates and toxic stress" (Mindful Schools, 2007, para. 1). This program provides a curriculum that is easily implemented into the school day. The overarching goal of Mindful Schools is for teachers to understand the emotions and stress that students in today's society increasingly experience. Therefore, courses are offered for teachers that equip them with the ability to utilize mindfulness-based interventions to work with students on these issues. An evaluation of the Mindful Schools program revealed that $89 \%$ of students have shown "improved emotional regulation" (Mindful Schools, 2007, Impact section).

Calm Schools took a different approach and rather than writing curriculum, created an application that can be downloaded onto a phone or computer and utilized in the classroom (Calm.com Inc., 2020). The application is free to teachers across the world and provides them with the necessary resources to engage students in calming activities. Breathing exercises, calming music, and guided meditation sessions with a focus on topics such as anxiety, stress, self-esteem, and happiness are all components of this application. There is also a "Daily Calm" feature to get the day started in a peaceful and calm manner (Calm.com Inc., 2020).

Another application, Headspace, was initially created with businessmen in mind. However, further development allowed everyone access to mindful practices (Headspace, 2010). The application consists of guided meditation exercises for work, children, sleep, focus, stress, and anxiety. Meditation is geared towards children and includes themed exercises to help them focus, be kind, calm down, go to sleep, and wake up. These exercises are further grouped for different age groups including under five-years-old, six to eight-years-old, and nine to twelve-years-old.

The Momentous School, founded in 1997, has monitored students for more than twenty years by tracking their progression through mindfulness-based education (Kinder, 2017). The school is focused on protecting students from the harmful stress of today's society. They use mindfulness to teach students to focus on "regulating their nervous system" and to "manage their internal world regardless of what comes at them externally" (Kinder, 2017, para. 7). 
A two-year study was conducted at the Momentous School which compared students who received mindfulness-based interventions with those who received an education without mindfulness. This study had a particular focus on academic achievement, as students were followed from pre-kindergarten to kindergarten (Thierry et al., 2016). After completing pre-kindergarten, students who received mindfulness training "showed improvements in teacher-reported executive function skills, specifically related to working memory and planning and organizing, whereas students in the control group showed a decline in these areas" (Thierry et al., 2016, p. 2). Students were followed into kindergarten and results indicated that by the end of the year the students who had practiced mindfulness had increased vocabulary skills compared to students in the control group.

\section{Purpose of the Study}

There is an increasing trend in the literature examining the impact of mindfulness-based interventions and programs for elementary-aged students. However, minimal studies have focused on the impact that mindfulness-based yoga interventions may have on the well-being of elementary schoo students, and how classroom teachers perceive this practice. Therefore, the purpose of this study was to examine the impact of mindfulness-based yoga on fifth-grade students' perceived anxiety and stress and to garner the teacher's perceptions of the intervention. The following research questions guided this study:

1. How do mindfulness-based yoga interventions impact fifth-grade students' perceived anxiety and stress levels in a mathematics classroom?

2. What is a fifth-grade classroom teacher's perceptions of mindfulness-based yoga interventions?

\section{Methods}

The present study took place in three fifth-grade mathematics classes at an intermediate school in Northwest Mississippi for three months during Fall 2018. After approval was received from the University's Institutional Review Board, written consent was obtained from a fifth-grade mathematics teacher. Participants were fifth-grade students in the teacher's classes; therefore, a convenience sample was utilized. The researchers communicated through the consent letter sent home that each student must complete the intervention as a part of their classroom activity; however, if they chose not to obtain consent or provide assent, students did not complete the pre- or post-questionnaire. Fifty-eight students (76\%), among three classes, ranging from ages 10-12 chose to participate with parental consent and student assent. Demographics of the participants were White (72.41\%), African-American (20.69\%), Hispanic (3.45\%), and Asian (3.45\%). Participants in the first class consisted of seven males and five females. The second class consisted of eight male and thirteen female participants. The third class consisted of twelve male and thirteen female participants. In total, there were 27 male participants (46.55\%) and 31 female participants (53.45\%).

Participants were separated into classes based on ability level. Each student's level was determined by his/her state test scores from the previous year. The first class consisted of students with the lowest scores, with the exception of students with an Individualized Education Program - 12 of these students participated in the study (57.14\%). Additionally, one student participant in the first class was on Tier 3 remediation for mathematics and English, while another student participant was on Tier 2 remediation for mathematics and Tier 3 remediation for English and behavioral interventions. The second class consisted of students in the average range -21 of these students participated in the study $(77.78 \%)$; there were no stu- dents in the tier process. The third and final class consisted of advanced students -25 of these students participated in the study (89.29\%). One student participant in this class was on Tier 3 remediation for behavioral interventions.

Procedures

Design

This study utilized both quantitative and qualitative measures to collect data regarding the impact of mindfulness-based yoga interventions on the perceived anxiety and stress of students in three fifth-grade mathematics classrooms. Thus, a concurrent mixed methods design was used (Creswell et al., 2003), as the qualitative data were utilized to supplement the quantitative findings. Quantitative data were collected first through a pre-questionnaire. The interventions were then conducted and the study concluded with a post-questionnaire survey and classroom teacher interview.

The intervention phase of the study began on Monday, November 5th, 2018, after baseline data were collected for three weeks. A student teacher conducted all of the mindfulness-based yoga interventions at the beginning of every class period for five minutes - 7:35- 7:40 a.m., 11:32-11:37 a.m., and 1:07- 1:12 p.m. The interventions were a series of guided breathing exercises and stretches that brought students' attention to their breath and helped them relax before the class began (See Appendix A). During each breathing exercise, the student teacher gave students a few seconds to quietly find a comfortable personal space. They had the option to remain at their desk, stand up, sit on the floor, or lay down. Once in their space, for example, a counted breathing exercise was completed. Students were given a designated number of counts to breathe in and out. They could either close their eyes or let them remain open. The exercise began by breathing in and slowly counting up to the designated number while the students followed along silently. Students then released their breath and exhaled out as the student teacher counted down from the designated number. Following the breathing exercises, students completed light yoga stretches such as downward dog, butterfly pose, and tree pose while light music played in the background. The Headspace application was also utilized throughout the intervention which provided the students with a period of guided meditation (See Figure 1).

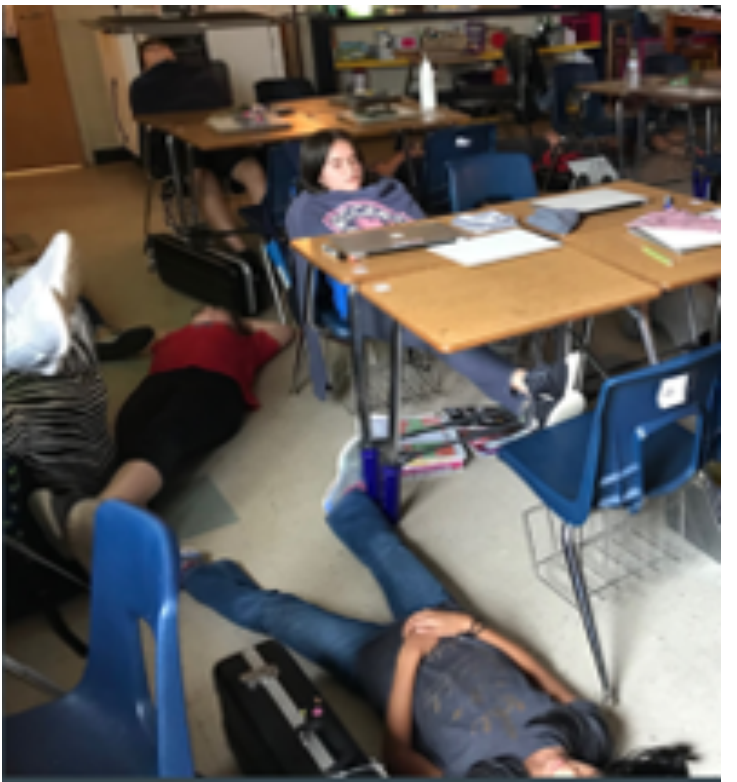

Figure 1. Students completing a mindful breathing exercise in their own space

At the conclusion of the intervention phase of the study, the 
students completed a post-intervention questionnaire. The questionnaire was anonymous and identical to the prequestionnaire. Students placed their answers in an envelope so that they could not be identified. At the conclusion of the study the resercher also interviewed the classroom teacher which enabled the researchers to obtain further insight into the classroom teacher's perceptions of the intervention.

\section{Data Collection}

\section{Questionnaire}

The questionnaire utilized during this study was adapted from the School Experience Survey created by the Community and Youth Collaborative Institute at Ohio State University (Anderson-Butcher et al., 2016) (See Appendix B). Participants completed this questionnaire at the beginning of the study and again at the conclusion of the study. The questionnaire was anonymous and consisted of thirty-two questions regarding academic motivation, school connectedness, academic pressure, college and career readiness, internalizing behaviors, on-task behaviors, and student demographics. For the purpose of this study, the researchers only utilized for interpretation the statements on the questionnaire within the factors of internalizing behaviors, on-task behaviors, and student demographics. For each of the statements, students were asked to circle one of four options - " 4 - YES!", "3 - Yes", "2 - No", or “1 - NO!" according to how much they agreed or disagreed with the statement. Validity of the School Experience Survey was determined through a confirmatory factorial analysis utilizing maximum likelihood estimation. The factor variance was estimated and no covariances between uniquenesses were modeled. An asymptotic covariance matrix was utilized and the overall fit of the model to the data revealed a good fit, wherein the squared multiple correlations averaged . 44 and the confirmatory factor analysis loadings for the questions utilized within this study ranged from .53-.75 (Anderson-Butcher et al., 2016).

\section{Semi-Structured Interview}

At the conclusion of the study, the primary researcher conducted a semi-structured interview with the classroom teacher. The interview took place in the teacher's classroom at the end of the school day and consisted of questions that guided the discussion (See Appendix C). Interview questions derived from the study's research questions illuminated quantitative survey data findings regarding the effect of the interventions on students' perceived anxiety and stress. The researcher utilized unscripted follow up questions to clarify any thoughts or misunderstandings and further probe the research topic.

\section{Data Analysis}

The researchers analyzed the questionnaire results by placing results for each question into a spreadsheet and then calculating the average change from the pre-intervention questionnaire to the post-intervention questionnaire. For every "YES!" the researchers recorded a four, for every "Yes" the researchers recorded a three, for every "No" the researchers recorded a two, and for every "NO!" the reserchers recorded a one. Next, the researchers derived the numerical average (mean) for answers within the following categories: (a) all classes; (b) individual class; (c) male students by individual class; (d) female students by individual class; (e) each male student; ( $f$ ) each female student; $(g)$ each student with attention deficit hyperactivity disorder; and (h) each student without attention deficit hyperactivity disorder. The researchers then placed results for each category into bar graphs to display the findings. The overall results were compared between the pre- and post-intervention questionnaire. Lastly, the researchers compared the pre- and post-questionnaire averages to determine the percentage change and the averages were compared across the three classes, females to males, and students diagnosed with attention deficit hyperactivity disorder to those not diagnosed with attention deficit hyperactivity disorder.

The primary researcher audio recorded and transcribed the interview with the classroom teacher. Transcripts were analyzed through a coding process to identify any discernible patterns between the interview and students' questionnaire results. This coding process entailed the unitization of data into sizable chunks that were placed into a spreadsheet (Lincoln \& Guba, 1985). Both researchers employed the constant comparison method (Lincoln \& Guba, 1985) after coding occurred and patterns were used to determine what might cause students' perceived anxiety and stress to elevate during certain times of the day. Excerpts from the findings are provided in the results section below and examples of each theme are identified.

\section{Results}

Overall findings of the students' pre- and post-questionnaire indicated that on average, students' perceived a slight increase in anxiety and a perceived decrease in their stress levels. Across all three classes, students reported an average increase of $1.9 \%$ in perceived anxiety levels and an average decrease of $9.29 \%$ in perceived stress levels in response to the questionnaire.

\section{Results by Gender}

All male participants across the three classes reported an average decrease of $2.22 \%$ in perceived anxiety levels (See Figure 2) and an average decrease of $20.63 \%$ in perceived stress levels (See Figure 3). All females across the three classes reported an average increase of $5 \%$ in perceived anxiety levels and no change in perceived stress levels.

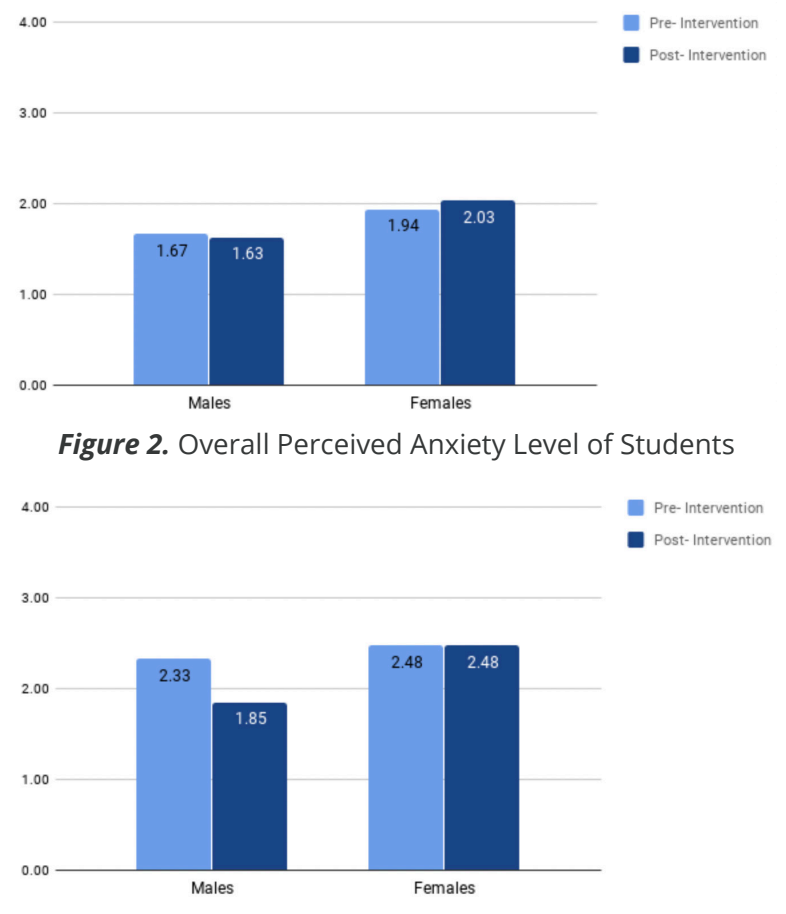

Figure 3. Overall Perceived Stress Level of Students

\section{Results by Ability Level and Gender}

In the first class, males reported a decrease of $16.67 \%$ in perceived anxiety levels and an average decrease of $31.58 \%$ 
in perceived stress levels, while females in the same class reported an average decrease of $9.09 \%$ in perceived anxiety levels and an average increase of $7.69 \%$ in perceived stress levels (See Figures 4 and 5).

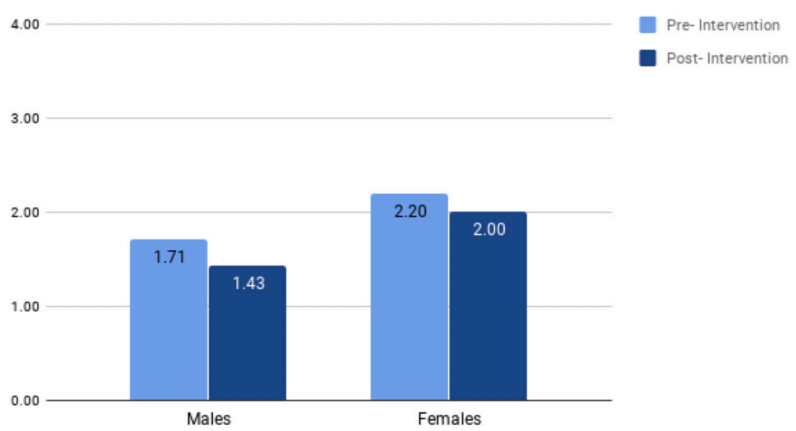

Figure 4. Perceived Anxiety Levels of Remedial Students

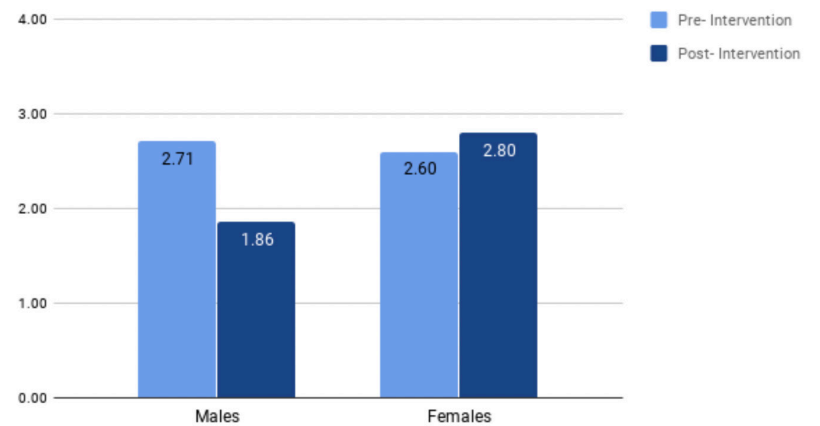

Figure 5. Perceived Stress Levels of Remedial Students

The second class consisted of average level students. Males in this class reported an average increase of $9.09 \%$ in perceived anxiety levels and an average decrease of $25 \%$ in perceived stress levels, while the females in the same class reported no change in perceived anxiety levels or stress levels (See Figures 6 and 7).

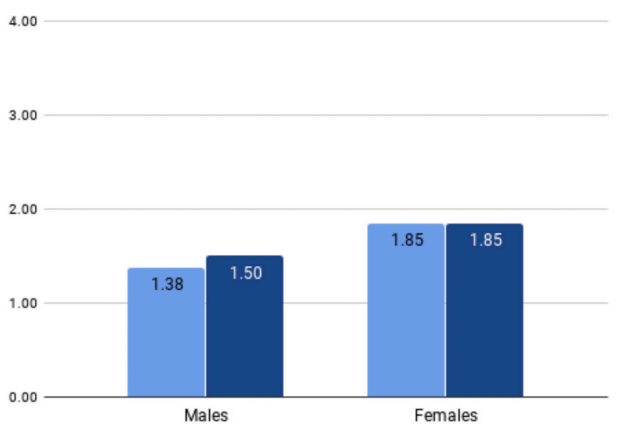

Figure 6. Perceived Anxiety Levels of Average Students

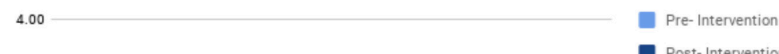

- Post-Intervention

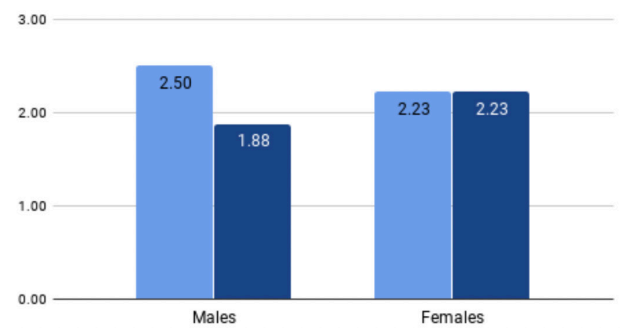

Figure 7. Perceived Stress Levels of Average Students

The third class, comprised of advanced students, reported an average decrease of $8.33 \%$ in perceived anxiety levels in male students and no change in perceived stress levels, while the females in the same class reported an average decrease of $2.86 \%$ in perceived anxiety levels and an average increase of $16 \%$ in perceived stress levels (See Figures 8 and 9).

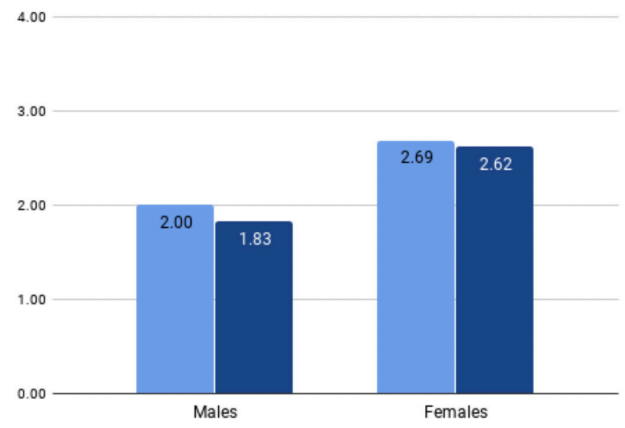

Figure 8. Perceived Anxiety Levels of Advanced Students

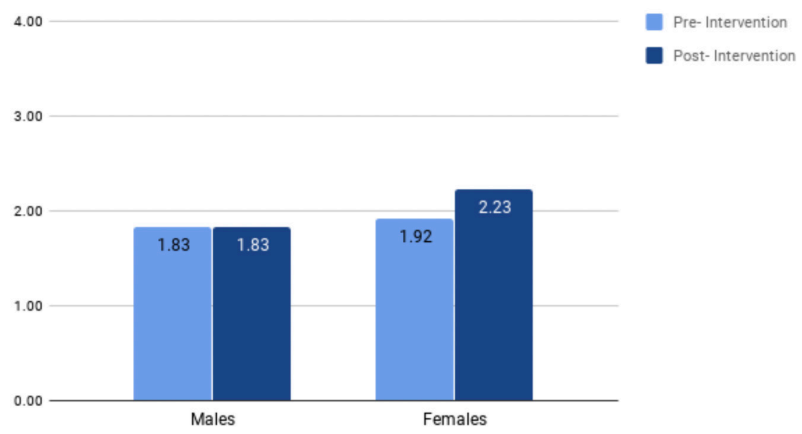

Figure 9. Perceived Stress Levels of Advanced Students

Results on Anxiety and Stress for Students with Attention Deficit Hyperactivity Disorder

Overall, the five students who stated that they had been diagnosed with attention deficit hyperactivity disorder, reported an average decrease of $22.08 \%$ in perceived anxiety levels and an average increase of 3.9\% in perceived stress levels. The remaining students not diagnosed with attention deficit hyperactivity disorder reported an average increase of $5.03 \%$ in perceived anxiety levels and an average decrease of $10.58 \%$ in perceived stress levels. The students diagnosed with attention deficit hyperactivity disorder in the first class reported an average decrease of $14.29 \%$ in perceived anxiety levels and an average increase of $33.33 \%$ in perceived stress levels. The students diagnosed with attention deficity hyperactivity disorder in the second class reported an average decrease of $16.67 \%$ in perceived anxiety levels and an average decrease of $6.67 \%$ in perceived stress levels. The third class had no data to report.

\section{Class Results on Anxiety and Stress by Ability Level}

Students in the first class consisted of remedial students and students with an Individualized Education Program. Results for this class indicated an average decrease of $13.04 \%$ in perceived anxiety levels and an average decrease of $15.6 \%$ in perceived stress levels. Students in the second class consisted of average students. Findings from this class revealed an average increase of $2.86 \%$ in perceived anxiety levels and an average decrease of $10.2 \%$ in perceived stress levels. Students in the third class consisted of advanced students. Reports noted an average increase of $8.51 \%$ in perceived anxiety levels and an average decrease of $5.08 \%$ in perceived stress levels was reported for this class (See Figures 10 and 11).

\section{Interview}

In addition to the quantitative data collected, the primary 


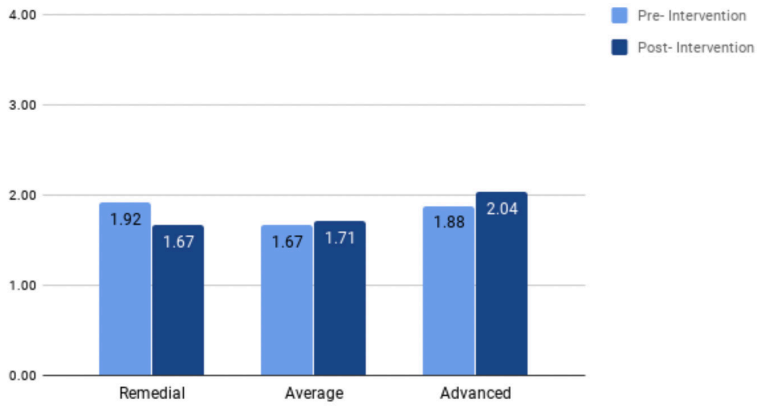

Figure 10. Perceived Anxiety Levels of Students by Ability Level

researcher also garnered qualitative data regarding the classroom teacher's perceptions of the impact of the mindfulness-based yoga intervention. While the quantitative findings revealed that some of the students felt a change in their anxiety and stress levels throughout the intervention, the teacher's interview provided further insight and illuminated some points that may not have emerged in the quantitative data. Three themes emerged from the interview data: (a) teacher perceptions of students' anxiety and stress in the classroom; (b) transfer of mindfulness-based yoga skills; and (c) creating a positive transition.

Teacher Perceptions of Students' Anxiety and Stress in the Classroom

Most teachers develop perceptions of their students' behaviors based on daily anecdotal observations. In alignment with the literature regarding an increase in students' anxiety and stress levels due to increased academic expectations, the teacher noted several times throughout the interview that the students consistently "exhibited behaviors that were indicative of anxiety and stress." It is important to keep in mind that students will bring stressors from home with them to school. Subsequently, behaviors that manifest at school may also be due to external factors. However, when the teacher was asked about her perceptions of the students' stress levels regarding school work and standardized testing, the teacher noted the following: "I would say the majority of them are stressed, but I'm sure 10 percent are going to stress and have anxiety no matter what." When analyzing interventions that aim to reduce anxiety and stress in the classroom it is important to keep in mind the social and home variables that play a role in the stress levels of children. Nevertheless, the teacher noted that students had made anecdotal comments to her and "expressed" how much the mindfulness-based yoga interventions had helped them "deal with anxiety and stress in general."

The teacher's thoughts regarding her perception that a majority of students have anxiety and stress anyway is important to take into consideration when developing a plan to mitigate what students encounter on a daily basis. It might be just a quick two to five-minute mindfulness transition that a teacher incorporates into the classroom if the perception and observations of one's students' indicates somewhat low levels of anxiety and stress. However, a classroom full of students exhibiting higher levels of troubling behaviors due to high levels of anxiety and stress may necessitate more intensive interventions or multiple mindfulness-based yoga sessions throughout the day. When interviewed, the following anecdote was expressed by the teacher about her perceptions of students' anxiety and stress in the classroom and how she would proceed forward with mindfulness-based yoga interventions:

I might do it everyday, but I might go down to not just the Headspace where the guy is talking, but instead use the music and just kind of mix it up. It would definitely be more of a mindful thing. You know, just based on what I have seen and observed.

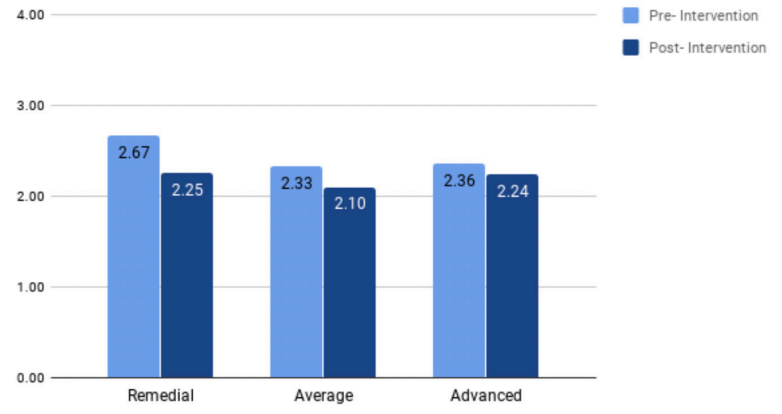

Figure 11. Perceived Stress Levels of Students by Ability Level

(Classroom Teacher - Fifth-Grade)

Transfer of Mindfulness-Based Yoga Skills

With any new method, intervention, or strategy that is employed in the classroom, it is important to ensure that it is effective and transferrable. One way to determine effectiveness is to assess students' abilities to apply it in a new setting or context. Throughout the interview the classroom teacher indicated that students employed the mindfulness-based yoga strategies even when the student teacher was not there. Additionally, the classroom teacher chose to employ and adapt some of the methods that the student teacher had utilized during the study. During the interview, the teacher also noted that the students mentioned they were "using mindful breathing outside of class to manage anxiety and stress and to help them go to sleep and stop racing thoughts." This anecdote indicates that the students were applying the use of breathing techniques as a mechanism beyond the classroom to help reduce their anxiety and stress. The classroom teacher was also emphatic that some of the most positive changes occurred on "test taking days" as noted below:

\begin{abstract}
...definitely in test taking. I think even some of them will come in on test days, but some of the girls for sure will come in and they are like 'okay let me find my headspace for a minute. Let me chill out. You know I am about to take a test, because they do have a lot of test anxiety and they just take a moment to breathe and then I will actually play some of the meditation music in the background to kind of go along with everything you have been doing because I have seen how much it helps and it just kind of eases them right through it. (Classroom Teacher Fifth-Grade)
\end{abstract}

In addition to utilizing mindful breathing techniques before tests in the intervention classroom, the classroom teacher indicated that the students mentioned they were "using mindful breathing before tests in other classes as well." The teacher noted that she always "notes a change in the stress and anxiety levels of students around test days." However, from the beginning of the intervention to the end of the intervention, the teacher stated that "the stress and anxiety seemed to lessen as students progressively participated in the interventions."

\section{Creating a Positive Transition}

Although the sole purpose of the mindfulness-based yoga intervention was not to examine its impact on factors beyond student-related anxiety and stress, an unexpected theme arose in the teacher interview. This outcome encompassed the ability of mindfulness-based yoga to act as a tool to facilitate effective classroom transitions. Most of the research on mindfulness in the classroom reveals the positive physical, academic, and health benefits that occur as a result of implementation but lacks the connection to how that may impact the instructional process. Because transitions are one of the most critical facets of effective instruction, it is important to note how it emerged in the teacher interview. 
The transition times between the mindfulness-based yoga interventions and when students began working were not measured quantitatively. However, the teacher noted, "I think it helps them transition in a more positive way, but quicker because you have to take the time to do that. So, I don't know if it is faster, but I think it is definitely more of a positive transition."

When students enter fifth-grade in the United States, they are usually exposed to a new system of academic work. Educators expect students to move from acquiring all academic subjects in one classroom during their lower elementary school years to traversing multiple classrooms throughout the day that are compartmentalized into subjects in the upper elementary school. Within this new system, students must transition and self-regulate rapidly into multiple environments throughout the school day. Students have to learn this skill and as the teacher mentioned, "students struggle going from class to class, in the hallways, coming in, settling down. It is definitely a struggle." This struggle stems from students' inability to adapt from moving into an academic setting to a social setting and then back into an academic setting. When answering how the teacher saw the mindfulness-based yoga interventions as helpful for students, she noted: "It has helped because my students know that they are coming in to do the mindfulness. They come in, calm down, and it prepares them to move forward." This calm is the self-regulation that occurs when students are offered the opportunity to breathe and through their breath they become aware of the present moment by focusing on what they need to do with their body and mind to move forward to the next task. When probed further about the transformation the teacher had witnessed regarding the transition from hallway to student work, she noted that it has "majorly improved." While "majorly" is not quantifiable, it is important to note that because of the positive connection to the mindfulness strategies for students, they "like it," which the teacher then noted, "I like that they like it." The teacher revealed that she plans to continue using some of the mindfulness-based yoga strategies because of the positive difference and transformation she has seen it make in her classroom.

\section{Discussion}

The present study examined the impact of mindfulness-based yoga on students perceived anxiety and stress levels. In congruence with previous research (Ager et al., 2015; Folletto et al., 2016; Semple, 2010; Stueck \& Gloeckner, 2007;), it could be posited that results of this study support the claim that mindfulness-based yoga interventions in the classroom can improve students' perceived anxiety and stress levels and improve overall classroom effectiveness.

Although the most impactful results emerged from students in the remedial class, the results revealed varying effects on each group. Male participants reported the greatest benefits, with a slight decrease in perceived anxiety and a large decrease in perceived stress. In particular, males in the remedial class reported the greatest changes, with the highest percentage decrease in perceived anxiety and the second highest decrease in stress. Similarly, Parker et al. (2014) found that males benefited most from mindfulness interventions in regards to their self-control. In further alignment with previous research (Parker et al., 2014), females in the remedial class reported an average decrease in perceived anxiety levels. This study's results are also in alignment with previous research (Semple, 2010) which revealed that mindfulness-based cognitive therapy may be beneficial for remedial students' perceived anxiety levels.

Findings from the classroom teacher's interview further support the notion that there was an "obvious" decrease in anxiety and stress, "especially around test days." In agreement with the teacher's corroboration of the quantitative findings, Cars- ley et al. (2015) reported an overall improvement in students' test anxiety when mindfulness-based yoga interventions were employed within the classroom. However, it is important to take into consideration that according to the questionnaire responses not every student reported the same positive results throughout the present study. In regards to students' anxiety levels, the questionnaire revealed that both the average and advanced level students indicated a slight rise in perceived anxiety levels between the pre- and post-intervention questionnaire. The females in these two classes also reported a rise in their perceived anxiety levels. This may have been a result of a lack of prior knowledge regarding yoga and mindfulness, a change in stressors, distractions, or academic content between the pre- and post-intervention questionnaire. In contrast to these students' responses, the classroom teacher noticed a general change in all of her classes throughout the intervention. The teacher's observations were that overall, students' anxiety had improved since beginning the intervention, specifically in regard to testing. This finding is similar to previous studies focused on mindfulness in the classroom (Mindful Schools, 2007; Parker et al., 2014). Anecdotes from the interview also revealed changes in students' behaviors surrounding test dates throughout the intervention, inclusive of less chaotic behavior, more calm test taking and preparation, and less concerned comments about grades. These observational anecdotes suggest a perceived decrease in anxiety and stress in students, further supporting the use of mindfulness-based yoga interventions in the classroom setting.

The reduction in anxiety and stress also manifested itself in the form of more positive classroom transitions. As an indicator of pedagogical effectiveness, this outcome reveals the importance of acknowledging students' anxiety and stress in the classroom and providing appropriate interventions to assist with students' learning and the teacher's ability to create an effective instructional environment. The utilization of mindfulness-based yoga interventions as classroom transitions may afford more effective teaching opportunities while enabling students to cope with the many daily stressors of life (Napoli et al., 2005).

\section{Limitations}

Results of this study indicated an overall positive change in perceived stress, particularly in remedial males. However, there are limitations within the research that must be taken into consideration. Conducting research in a classroom has its hindrances, due to constantly changing school schedules. Activities such as pep rallies and character education time adjusted the students' daily schedule and routine, often leaving many students confused or tardy. Interruptions from administration, other teachers, or other students also disrupted the intervention throughout the study. These distractions and changes introduced deviations from the students' focus, which may have affected their perceived levels of stress and anxiety. Furthermore, the daily academic foci might have changed students' perceived anxiety and stress levels. The beginning of new material and concepts could increase perceived anxiety and stress among some students as they worked towards grasping the ideas presented. Other students feel perceived stress and anxiety with mathematics in general (Kucian et al., 2018; Mutlu, 2019). Future research should expand the number of classrooms examined with an increased variety of participants to build upon the findings of this study.

\section{Conclusion}

In summary, this study provides a platform and further support for the use of mindfulness-based yoga interventions in the elementary classroom. As a novel approach in the realm of education to addressing increased pressure and stress that children in the 21 st century encounter, this study revealed that mindfulness-based yoga interventions did not hinder stu- 
dents' emotional well-being. On the contrary, such interventions suggest an advantageous means to assist in the development of the cognitive, social-emotional, and physical domains, while simultaneously promoting a positive classroom environment that enables effective instruction and learning to transpire.

\section{References}

Ager, K., Albrecht, N., \& Cohen, M. (2015). Mindfulness in schools research project: Exploring students' perspectives of mindfulness. Scientific Research Publishing, 6(7), 896-914. http://dx.doi.org/10.4236/ psych.2015.67088

Anderson-Butcher, D., Amorose, A., lachini, A., \& Ball, A. (2016). Community and youth collaborative school experience surveys. The Ohio State University. Retrieved from:http://cayci.osu.edu/wp-content/uploads/2016/05/ 2016-CAYCI-ES-Survey_FINAL.pdf

Bellinger, D., DeCaro, M., \& Ralston, P. (2015). Mindfulness, anxiety, and high-stakes mathematics performance in the laboratory and classroom. Consciousness and Cognition, 37, 123-132. http://dx.doi.org/10.1016/j. concog.2015.09.001

Blair, C., \& Razza, R. P. (2007). Relating effortful control, executive function, and false-belief understanding to emerging math and literacy ability in kindergarten. Child Development, 78(2), 647-663. http://dx.doi. org/10.1111/j.1467-8624.2007.01019.x

Broderick, P., \& Metz, S. (2009). Learning to BREATHE: A pilot trial of mindfulness curriculum for adolescents. $A d$ vances in School Mental Health Promotion, 2(1), 35-46. http://dx.doi.org/10.1177/2156587217696928

Calm.com, Inc. (2020). Calm. (Version 4.28) [Mobile Application Software]. Retrieved http://itunes.apple.com

Carsley, D., Heath, N., \& Fajnerova, S. (2015). Evaluating the effectiveness of a mindfulness coloring activity for test anxiety in children. The Journal of Applied School Psychology, 31(3), 239-255.http://dx.doi.org/10.1080/ 15377903.2015.1056925

Creswell, J. W., Plano Clark, V. L., Guttman, M. L., \& Hanson, W. E. (2003). Advanced mixed methods research designs. In A. Tashakkori and C. Teddlie ( Eds), Handbook on mixed methods in the behavioral and social studies. Sage Publications.

Dee, T., \& Jacob, B. (2010). The Impact of No Child Left Behind on Students, Teachers, and Schools. Brookings Papers on Economic Activity. Retrieved from: https://www.brookings.edu/wp-content/uploads/2010/09/2010b_bpea_dee.pdf

Donahoe-Fillmore, B. \& Grant, E. (2019). The effects of yoga practice on balance, strength, coordination, and flexibility in healthy children ages 10-12 years. Journal of Bodywork and Movement Therapies, 23(4). http://dx.doi.org/10.1016/j.jbmt.2019.02.007

Eccles, J. S., \& Roeser, R. W. (2009). Schools, academic motivation, and stage-environment fit. In R. M. Lerner \& L. Steinberg (Eds.), Handbook of adolescent psychology: Individual bases of adolescent development (p. 404-434). John Wiley \& Sons Inc. http://dx.doi. org/10.1002/9780470479193.adlpsy001013
Every Student Succeeds Act, 20 U.S.C. § 6301 (2015). https:// www.congress.gov/114/plaws/publ95/PLAW114publ95.pdf

Folletto, J., Pereira, K., \& Valentini, N. (2016). The effects of yoga practice in school physical education on children's motor abilities and social behavior. International Journal of Yoga, 9(2), 156-162. http://dx.doi. org/10.4103/0973-6131.183717

Garey, J. (n.d.). Mindfulness in the classroom. Child Mind Institute. Retrieved from https://childmind.org/article/ mindfulness-in-the-classroom/

Greater Good Magazine. (n.d.). What is mindfulness? Retrieved from https://greatergood.berkeley.edu/topic/mindfulness/definition\#why-practice

Hagen, I., \& Nayar, U. (2014). Yoga for children and young people's mental health and well-being: Research review and reflections on the mental health potentials of yoga. Front Psychiatry, 5(35), 1-6. http://dx.doi. org/10.3389/fpsyt.2014.00035

Hanson, R. (2011) How to Trick Your Brain for Happiness. Greater Good Magazine. Retrieved from https://greatergood.berkeley.edu/article/item/how_to_trick your_brain_for_happiness

Headspace. (2020). Headspace: meditation and sleep (Version 3.115.2) [Mobile Application Software]. Retrieved from http://itunes.apple.com

Hennessey, B. A. (2007). Promoting social competence in school-aged children: The effects of the Open Circle Program. Journal of School Psychology, 45(3), 349-360. http://dx.doi.org/10.1016/j.jsp.2006.11.007

Herman, K., Hickmon-Rosa, J., Reinke, W. (2017). Empirically derived profiles of teacher stress, burnout, self-efficacy, and coping and associated student outcomes. Journal of Positive Behavior Interventions, 20(6). http:// dx.doi.org/10.1177/1098300717732066

Holas, I., \& Huston, A. (2012). Are middle schools harmful? The role of transition timing, classroom qualities and school characteristics. Journal of Youth and $\mathrm{Ad}$ olescence, 41(3), 333-345. http://dx.doi.org/10.1007/ s10964-011-9732-9

Jones, B. D., \& Egley, R. J. (2004). Voices from the frontlines: teachers' perceptions of high-stakes testing. Education Policy Analysis Archives, 12(39). http://doi. org/10.14507/epaa.v12n39.2004

Jones, M., Jones, B., Hardin, B., Chapman, L., Yarbrough, T., \& Davis, M. (1999). The impact of high-stakes testing on teachers and students in North Carolina. The Phi Delta Kappan, 81(3), 199-203.

Kohl, H. W., \& Cook, H. D. (2013). Physical activity, fitness, and physical education: Effects on academic performance. Educating the Student Body: Taking Physical Activity and Physical Education to School (pp. 161-196). The National Academy Press.

Kinder, M. (2017). Why mindfulness belongs in the classroom. Mindful. Retrieved from https://www.mindful. org/why-mindfulness-belongs-in- the-classroom/

Kucian, K., McCaskey, U., Tuura, R., \& von Aster, M. (2018) Neurostructural correlate of math anxiety in the 
brain of children. Translational Psychiatry, 8(1), 1-11.

Kyriacou, C. (2001). Teacher stress: Directions for future research. Educational Review, 53(1), 27-35. http://dx.doi. org/10.1080/00131910120033628

Lincoln, Y.S., \& Guba, E.G. (1985). Naturalistic Inquiry (vol. 75). Beverly Hills, CA: Sage.

Lund, J. (2010). Educating the whole child. Viewpoint, 81(5), 3-10. http://dx.doi.org/10.1080/07303084.2010.10598 468

Mendelson, T., Greenberg, M. T., Dariotis, J. K., Gould, L. F., Rhoades, B. L., \& Leaf, P. J. (2010). Feasibility and preliminary outcomes of a school-based mindfulness intervention for urban youth. Journal of Abnormal Child Psychology, 38(7), 985-994. http://dx.doi.org/10.1007/ s10802-010-9418-x

Mindful Schools. (2007). Our approach to supporting mindfulness in education. Retrieved from https://www.mindfulschools.org/about-mindfulness/our-approach/

Mutlu, Y. (2019). Math anxiety in students with and without math learning difficulties. International Electronic Journal of Elementary Education, 11(5), 471-475.

Napoli, M., Krech, P. R., \& Holley, L. (2005). Mindfulness training for elementary school students: The attention academy. Journal of Applied Psychology, 21(1), 99-125. http://dx.doi.org/10.1300/J370v21n01_05

No Child Left Behind Act of 2001, P.L. 107-110, 20 U.S.C. § 6319 (2002).

Open Circle. (n.d.). Curriculum. Retrieved from https://www. open-circle.org/our-approach/curriculum

Open Circle. (n.d.). Open Circle. Retrieved from http://www. open-circle.org/

Open Circle. (n.d.). Mindfulness. Retrieved from https://www. open-circle.org/resources/mindfulness

Parker, A., Kupersmidt, J., Mathis, E., Scull, T., \& Sims, C. (2014). The impact of mindfulness education on elementary school students: Evaluation of the master mind program. Advances in School Mental Health Promotion, 7(3), 184-204. http://dx.doi.org/10.1080/175473 0X.2014.916497

Pepping, C., O'Donovan, A., \& Davis, P. J. (2013). The positive effects of mindfulness on self-esteem. The Journal of Positive Psychology: Dedicated to furthering research and promoting good practice, $8(5), 376-386$. http://dx.doi.or g/10.1080/17439760.2013.807353

Razza, R., Raymond, K., \& Bergen-Cico, D. (2013). Enhancing preschoolers' self-regulation via mindful yoga. Journal of Child and Family Studies, 24(2), 372- 385. http://dx. doi.org/10.1007/s10826-013-9847-6

Reilly, E., Buskist, C., \& Gross, M. (2012). Movement in the classroom: Boosting brain power, fighting obesity. Kappa Delta Pi Record, 48(2), 62-66. http://dx.doi.org/10 $.1080 / 00228958.2012 .680365$

Semple, R., Lee, J., Rosa, D., \& Miller, L. (2010). A randomized trial of mindfulness-based cognitive therapy for children: Promoting mindful attention to enhance social emotional resiliency in children. Journal of Child and Family Studies, 12(2), 218229. http://dx.doi.org/10.1007/ s10826-009-9301-y
Sharf, R. (2015). Is mindfulness Buddhist? (and why it matters). Transcultural Psychiatry, 52(4), 470-484. http://dx.doi. org/10.1177/1363461514557561

Stueck, M., \& Gloeckner, N. (2005). Yoga for children in the mirror of the science: Working spectrum and practice fields of the training of relaxation with elements of yoga for children. Early Child Development and Care, 175(4), 371 377. http://dx.doi.org/10.1080/0300443042000230537

Thierry, K., Bryant, H., Nobles, S., \& Norris, K. (2016). Two-year impact of a mindfulness-based program on preschooler's self regulation and academic performance. Early Education and Development, 27(6), 805-821. http://dx. doi.org/10.1080/10409289.2016.1141616

Zenner, C., Herrnleben-Kurz, S., \& Walach, H. (2014). Mindfulness-based interventions in schools-a systematic review and meta-analysis. Frontiers in Psychology, 603(5). http://doi.org/10.3389/fpsyg.2014.00603 